\title{
Agama Dalam Pelukan Koruptor
}

\author{
Amalia Syauket \\ Fakultas Hukum, Universitas Bhayangkara Jakarta Raya \\ Email: amalia.syauket@dsn.ubharajaya.ac.id
}

Article info

Received: Ags 22, 2021 Revised: Sep 24, $2021 \quad$ Accepted: Oct 22, $2021 \quad$ Published: Dec 9, 2021

DOI: https://doi.org/10.31599/krtha.v15i2.788

Keywords : $\quad$ religion, formality, power, corruption

Abstract : At the normative level, all religions teach their adherents not to abuse their authority for personal gain. Religion also instructs us not to take the rights of others. However, the reality shows that a country with a majority religious community cannot be separated from corruptpractices. In fact, many cases of acute corruption are found in countries that have a strong religious identity, regardless of religion. Religious urges, along with an understanding of God in them, are embedded in the structure of the human mind and nerves. However, when the urge does not become a reality, without the support of appropriate circumstances, such as the influence of political or economic power. This qualitative research uses a rational and critical attitude, not based on any faith or religion, by prioritizing secondary data, to answer the research question, how is religion in the arms of the corrupt? Is Religion in the close arms of the corrupt? Because logically and ideally, someone who is religious and carries out his religion well will avoid corruption. From the various literatures in this study, it appears that religion in the arms of corruptors is only a formality at the level of the ritual dimension but has not been able to have an effect on the level of behavior at the level of morality, which has an impact on the separation between worship that is directly related to Allah SWT and worship that is related to religion. fellow human beings. Religion in the arms of corruptors, is only reflected in the practice of religious rituals, is still individual piety, not yet reflected in anti-corruption behavior socially. When religion becomes corrupt because of political and economic influence, it is abandoned.

Kata kunci : $\quad$ agama, formalitas, kekuasaan, korupsi

Abstrak : Pada tataran normatif, semua agama tentu mengajarkan pemeluknya agar tidak menyalahgunakan wewenang untuk kepentingan pribadi. Agama juga menitahkan agar kita tak mengambil hak orang lain. Namun, realitas menunjukkan negara dengan mayoritas umat beragama tidak ada yang lepas dari praktik korupsi. Bahkan, kasus-kasus korupsi akut banyak ditemukan di negara yang memiliki identitas agama kuat, apa pun agama itu. Dorongan beragama, beserta pemahaman tentang Tuhan di dalamnya, sudah tertanan di dalam struktur pikiran maupun syaraf manusia. Namun ketika dorongan tersebut tidak menjadi kenyataan, tanpa dukungan keadaan yang sesuai misalnya pengaruh kekuasaan politik maupun ekonomi. Penelitian kualitatif ini menggunakan sikap rasionalitas dan kritis, tidak berpijak pada iman atau agama apa pun, dengan mengutamakan data sekunder, untuk menjawab pertanyaan penelitian bagaimana agama dalam pelukan para koruptor? Apakah Agama berada dalam pelukan erat para koruptor? Karena Secara logis dan ideal, seseorang yang taat beragama dan menjalankan agama dengan baik akan terhindar dari korupsi. Dari berbagai literature dalam 
penelitian ini tampak bahwa agama dalam pelukan koruptor hanya sebagai formalitas saja pada tataran dimensi ritual belum mampu berefek pada tingkat perilakunya pada dimensi tataran moralitas, yang berdampak adanya pemisahan antara ibadah yang sifatnya hubungan langsung dengan Allah SWT dengan ibadah yang bersifat hubungan dengan sesama manusia. Agama dalam pelukan koruptor, baru tercermin pada praktek ritual agama semata, masih menjadi kesalehan individu, belum tercermin dalam perilaku anti korupsi secara sosial. Ketika beragama menjadi koruptor karena pengaruh politik maupun ekonomi, maka ia ditinggalkan.

\section{PENDAHULUAN}

Isu berkaitan hubungan antara ketaatan beragama dengan perilaku korupsi sangat sensitive. Karena Agama bagi bangsa Indonesia sangat sentral, nilai-nilai religius keagamaan itu bagi kita sudah sangat mengakar dan itu diwujudkan dalam bentuk secara konstitusi bahwa negara Republik Indonesia ini adalah berdasarkan Ketuhanan Yang Maha Esa.

Masyarakat Indonesia pada umumnya tergolong religius. Pada tataran normatif, semua agama tentu mengajarkan pemeluknya agar tidak menyalahgunakan wewenang untuk kepentingan pribadi. Agama juga menitahkan agar kita tak mengambil hak orang lain. Namun, realitas menunjukkan negara dengan mayoritas umat beragama tidak ada yang lepas dari praktik korupsi. Bahkan, kasus-kasus korupsi akut banyak ditemukan di negara yang memiliki identitas agama kuat, apa pun agama itu. ${ }^{1}$ Karena para pelakunya belum menyentuh kedalaman dan kekayaan yang ada di dalam agama-agama. ${ }^{2}$

Kedangkalan hidup beragama inilah yang membuat agama dengan mudah dijadikan pembenaran bagi kepentingan politik maupun ekonomi yang busuk. Kajian dalam penelitian ini bukanlah sebuah kajian tentang agama tertentu dengan tujuan untuk memahami keterkaitan agama dengan berbagai bidang kehidupan lainnya ${ }^{3}$.Dorongan beragama, beserta pemahaman tentang Tuhan di dalamnya, sudah tertanan di dalam struktur pikiran maupun syaraf manusia. Namun ketika dorongan tersebut tidak menjadi kenyataan, tanpa dukungan keadaan yang sesuai misalnya pengaruh kekuasaan politik maupun ekonomi, maka ia akan ditinggalkan. ${ }^{4}$

\footnotetext{
${ }^{1}$ https://mediaindonesia.com/kolom-pakar/136880/agama-kesalehan-ritual-dan-korupsi., di akses tgl.29 September 2021.

2 Syafiin Mansur: Jihad Berantas Korupsi Dalam Perspektif Kitab Suci Agamahttp://repository.uinbanten.ac.id/5147/1/2301-265-5787-1-10-20191128.pdf. di akses tgl. 5 Oktober 2021.

3 https://www.unpak.ac.id/khazanah-ramadhan/pandangan-islam-soal-korupsi-dan-hukumannyadi-akhirat-kelak. Di akses tgl. 5 Oktober 2021.

4 https://www.kompasiana.com/kianti/58b37da80e9373660ffa7383/kristiani-menilai-korupsi Kreator: Alshaura Putrikianti. Di akses tgl.5 Oktober 2021.
} 


\section{METODE PENELITIAN}

Penelitian ini menggunakan pendekatan kualitatif bertipe fenomenologi. Pendekatan ini seperti yang dijelaskan oleh Alase, fenomenologiadalah sebuah metodologi kualitatif yang mengizinkan peneliti menerapkan dan mengaplikasikan kemampuan subjektivitas dan interpersonalnya dalam proses penelitian eksploratori. Penelitian ini mengutamakan sumber data sekunder berupa studi pustaka bertujuan untuk menemukan suatu masalah untuk diteliti, mencari informasi yang relevan dengan masalah yang akan diteliti, mengkaji beberapa teori dasar yang relevan dengan masalah yang akan diteliti.

\section{PEMBAHASAN}

\section{Agama Sebagai Formalitas Belaka}

Agama apapun secara tekstual jelas-jelas melarang korupsi, namun dalam kenyataannya hingga kini masih terdapat pejabat legislatif, eksekutif, maupun yudikatif yang terjerat kasus korupsi. Masyarakat tidak menerima korupsi, namun anehnya 'memaklumi' praktik korupsi itu sendiri. Hal ini disebabkan karena tingkat religiusitas masyarakat masih sebatas pada level normatif atau keyakinan, dan belum berefek pada tingkat perilakunya, yang disebabkan karena minimnya integritas untuk mengamalkan apa yang diyakini.

Masyarakat seolah-olah telah membuat satu pemisahan antara ibadah yang sifatnya hubungan langsung dengan Allah SW'T dengan ibadah yang bersifat hubungan dengan sesama manusia. Padahal menepati janji adalah ibadah, membantu memudahkan urusan masyarakat adalah ibadah, menolak korupsi adalah ibadah, bekerja menepati waktu kantor adalah ibadah, tidak mencuri barang di kantor adalah ibadah, adil dalam memberikan layanan tanpa membedakan status sosial masyarakat adalah ibadah. Masyarakat menganggap kerja di kantor adalah kerja dunia yang tidak ada hubungannya dengan ibadah. Akibat dari pemahaman yang keliru ini, maka berbagai perilaku jahat terjadi di kantor. Masyarakat keliru dalam memahami ketaatan beragama dan juga belum mampu membawa sifat ketaatan dalam ibadah pada perilaku di kantor.

Ibadah difahami dalam arti yang sempit yaitu amalan yang sifatnya hubungan dengan Allah SWT. Datang ke masjid, membaca Al-Qur'an, sedekah kepada anak yatim dan fakir miskin, puasa pada bulan ramadhan, membayar zakat dan haji sebagai ibadah. Ini memang benar, semua amalan tersebut adalah ibadah. Tetapi perkara yang berhubungan dengan urusan di kantor, membantu urusan masyarakat, jujur dalam bekerja, 
tidak melakukan korupsi, menunaikan amanah, bekerja dengan integritas yang tinggi masih dianggap bukan ibadah. Ibadah yang mereka lakukan masih belum mampu melahirkan akhlak yang baik dalam memberi pelayanan kepada masyarakat. Karena agama hanya sebagai formalitas maka tidak mempunyai kemampuan untuk menolak yang tidak halal, karena beragama tanpa kesadaran dan tanpa pengamalan ajaran beragama yang benar, masih sebatas pada level normatif atau keyakinan, dan belum berefek pada tingkat perilakunya, yang disebabkan karena minimnya integritas untuk mengamalkan apa yang diyakini.

Terdapat suatu ambiguitas etik di kalangan masyarakat di mana semua agama melarang korupsi, mencuri, tetapi penganutnya membenarkan korupsi dengan alasan tertentu. Ada anggapan bahwa dosa korupsi bisa ditebus dengan amal sedekah dengan uang korupsi. Hal ini terjadi akibat pemahaman agama yang masih sebagai ritualitas belaka. Agama tak bisa sendirian melawan praktik korupsi. Batasan-batasan moral agama tidak cukup kuat untuk mendorong seseorang tetap bermoral ketika memperoleh peluang dan punya kekuasaan. ${ }^{5}$

Dengan demikian, secara mitos maupun magis, agama merupakan kerangka bertindak bagi individu dan masyarakat. Hubungan antara agama dengan pencegahan antikorupsi sendiri tercemin dari tulisan Douglas Beets yang menyatakan bahwa kepercayaan seseorang terhadap agama dapat menghindarkan seseorang dari tindakan korupsi. ${ }^{6}$

\section{Agama dan Kekuasaan}

Setiap agama tentu memiliki nilai dan ajaran yang membawa pengikutnya pada kebaikan. Ajaran-ajaran itu pula yang sepatutnya menjadi pegangan para pemeluknya dalam menjalankan kehidupan. Memang korupsi di Indonesia merajalela dikarenakan kekuasaan, kerakusan, dan lemahnya hukum serta tidak yakinnya terhadap ajaran agamanya. Oleh karena itu, pelaku korupsi berarti tidak pancasialis dan menghianti Pancasila karena mereka adalah para penjabat yang sudah bersumpah atas nama agama. Bahkan mengotori nilai-nilai Ketuhanan Yang Maha Esa dan kemanusian yang adil dan beradab. ${ }^{7}$

Pada dasarnya, semua kitab suci itu melarang melakukan kejahatan dan dosa, terutama yang menyangkut pencurian atau koruptor yang melakukan korupsi atau mencuri besar-besaran yang terjadi di Indonesia. Ada lima kitab suci yang dipercayai oleh

\footnotetext{
${ }^{5}$ Reza A.A. Wattimena, Untuk Semua yang Beragama, Kanisius,Yogyakarta,2020.

${ }^{6}$ Magnis-Suseno,Franz,Pemikiran Karl Mark,Gramedia, Jakarta,1999.

${ }^{7}$ Gramsci,Antonio,Selection from Prison Notebook, London,1971
} 
umat beragama di Indonesia, yaitu Al-Qur'an bagi Islam, Bibel atau Alkitab bagi Kristen [Katolik dan Protestan], Weda bagi Hinda, Tripitaka bagi Buddha dan Si Shu atau Su Si bagi Khonghucu. Semua kitab suci tersebut, membicarakan tentang pencuri milik orang lain atau milik pemerintah dengan istilah korupsi. Isi kandungan korupsi itu adalah mencuri, merampas atau perampok harta benda. Walaupun dalam kitab suci itu tidak menyebutkan kata korupsi namun menyebutkannya dengan istilah pencuri. ${ }^{8}$

Agama adalah salah satu ajaran pengikat manusia ${ }^{5}$. Orang-orang dengan berbagai latarbelakang, cara berpikir dan pola perilaku bisa hidup dibawah payung ajaran yang sama, berkat ajaran agama yang sama. Agama adalah sebentuk kekuasaan. Agama mengatur hidup banyak orang didalam payung ajaran agamanya. Bahkan korupsi dan penipuan masyarakat pun sering kali mencari pembenaran dari agama, supaya ia tidak ditinggalkan masyarakat luas ${ }^{5}$. Bahkan Karl Mark menyatakan bahwa agama justru diciptakan oleh penguasa demi kepentingan kekuasaan, guna mengontrol rakyatnya. Agama membuat rakyat menjadi tenang dan pasif, sehingga penguasa bisa menjadi tetap berkuasa, dan bahkan bisa memperbesar kekuasaannya ${ }^{9}$. Masih menurut Karl Mark, hubungan antara agama dengan kekuasaan adalah dua hal yang tak bisa dipisahkan begitu saja $^{10}$. Menurut Gramsci, hegomoni tidak hanya terjadi antarnegara, tetapi juga di dalam Negara. Untuk bisa duduk di pemerintahan atau memegang kekuasaan tertentu, orang harus memeluk agama tertentu. Sudah bukan rahasia lagi, kedudukan Presiden di Indonesia hanya bisa di pegang oleh pria beragama islam. Hal ini tidak tertulis secara resmi dalam undang-undang. Namun sebagai bentuk hegonomi, ia diikuti begitu saja, kerap kali tanpa sikap kritis. ${ }^{11}$

\section{Korupsi dan Kekuasaan}

Banyak Ragam definisi tentang korupsi. Dari beragam definisi tersebut korupsi didefinisikan sebagai perilaku yang menyimpang dari aturan etis formal yang menyangkut tindakan seseorang dalam posisi otoritas public yang disebabkan oleh motif pertimbangan pribadi, seperti kekayaan, kekuasaan dan status. ${ }^{12}$

\footnotetext{
${ }^{8}$ H.M.Arsyad Sanusi, Relasi antara Korupsi dan Kekuasaan,Jurnal Konstitusi vol 6 no.2,Juli 2009.

$9{ }^{10}$ Beets, Douglas. (2007). Global Corruption and Religion: An Empirical Examinition. Journal of Global Ethics3(1) Mei 2007.

${ }^{10}$ MODUL INTERNALISASI NILAI-NILAI AGAMA DALAM MEMBANGUN PEMIMPIN BERKARAKTER,KEMENTERIAN AGAMA RI BADAN LITBANG DAN DIKLAT PUSDIKLAT TENAGA ADMINISTRASI,2018.

$11{ }^{11}$ Artikel ini telah tayang di Kompas.com dengan judul "Korupsi Itu Bertentangan dengan Agama"Penulis Ilham Khoiri, di akses tgl.3 November 2021

${ }^{12}$ North,Charles M and Carl R.Gwin,"Religious Freedom and Unitended Consequences of State Religion",Southern Economic Journal 71:103-17.
} 
Korupsi dan kekuasaan, ibarat dua sisi dari satu mata uang. Korupsi selalu mengiringi perjalanan kekuasaan dan sebaliknya kekuasaan merupakan "pintu masuk" bagi tindak korupsi. Inilah hakikat dari pernyataan Lord Acton, guru besar sejarah modern di Universitas Cambridge, Inggris, yang hidup di abad ke 19. Dengan adagium-nya yang terkenal ia menyatakan: "Power tends to corrupt, and absolute power corrupt absolutely" (kekuasaan itu cenderung korup, dan kekuasaan yang absolut cenderung korup secara absolut)

Gambaran buram tentang kekuasaan dikarenakan kita sering merujuk praktek kekuasaan yang digenggam oleh politisi busuk. Akan tetapi adagium "kekuasaan itu cenderung korup" sebenarnya bisa ditepis ketika hadir kekuasaan yang amanah, adil, dan demokratis serta memiliki visi dan komitmen yang jelas tentang clean government and good governance. Kepemimpinan yang amanah adalah kepemimpinan yang mengedepankan teladan, transparansi dan akuntabilitas dalam memegang kekuasaan. Kepemimpinan yang adil adalah kepemimpinan yang mengedepankan supremasi hukum dan memberlakukan hukum bagi semua pihak atas dasar rasa keadilan masyarakat tanpa sikap diskriminasi. Kepemimpinan yang demokratis adalah kepemimpinan yang patisipatif dan dalam konstelasi check and balance antar unit-unit suprastruktur politik maupun infrastruktur politik. $^{13}$

Konsep kepemimpinan yang amanah di terdapat di semua ajaran agama, dengan istilah integritas, melayani seperti Kristus, dan mengambil keputusan melalui Roh Kudus pada agama Kristen $^{14}$, konsep pemimpinan yang amanah juga terdapat dalam ajaran Budhha seperti yang tersurat pada Dhammapada: 103 berupa Sïla, Aijjava (Ketulusan Hati) Ketulusan hati disini berarti seorang pemimpin harus memiliki kejujuran berusaha menghindari ucapan tidak benar, bohong, atau menipu (musāvāda $)$, dalam hal ini termasuk korupsi dan pencitraan diri agar dipandang baik.

Dengan demikian, korupsi bukan hanya salah dimata agama (dosa) dan hukum (kejahatan pidana luar biasa), tetapi juga adalah sesuatu yang salah dimata politik. Karena korupsi diidentifikasikan sebagai ancaman terbesar dalam suatu Negara pemerintahan yang demokratis, yang bukan saja mengancam demokrasi tetapi juga pembangunan ekonomi, keadilan sosial dan kepercayaan terhadap lembaga Negara. Dalam pandangan agama segala praktik korupsi dilarang karena merupakan pelanggaran HAM. Korupsi juga menifestasi pengingkaran terhadap amanah dan

13 Nye,J.S.,"Corruption and Political Development: A Cost benefit Analysis",American Political Science Review,Vol.LXI.no.2,1967.

14 Abayomi Alase, The interpretative Phinomenological Analisis (IPA) A Guide To a Good Qualitative Resiach Apporoach. International Journal Of Education and Literacy Studiens, Vol. 5 No. 2, April 2017. DOI: $10.757 /$ aiac. Ijels.v.5n.2p.9 
keadilan. Korupsi juga merupakan pengingkaran nikmat-nikmat Tuhan (Allah). Agamaagama, sebagaimana diungkapkan North \& Gwin (2004), memiliki ajaran yang mengatur tata kehidupan termasuk ajaran yang tidak menoleransi praktik-praktik korupsi dalam pelbagai dimensi ${ }^{12}$.

\section{KESIMPULAN}

Ketika Agama dalam pelukan koruptor, menjadikan agama tidak menjalankan fungsi utamanya untuk menciptakan kedamaian, berdasarkan keadilan dalam peradaban manusia. Agama dalam pelukan koruptor hanya sebagai formalitas saja pada tataran dimensi ritual belum mampu berefek pada tingkat perilakunya pada dimensi tataran moralitas, yang berdampak adanya pemisahan antara ibadah yang sifatnya hubungan langsung dengan Allah SWT dengan ibadah yang bersifat hubungan dengan sesama manusia. Agama dalam pelukan koruptor, baru tercermin pada praktek ritual agama semata, masih menjadi kesalehan individu, belum tercermin dalam perilaku anti korupsi secara sosial. Ketika beragama menjadi koruptor karena pengaruh politik maupun ekonomi, ada dorongan kebutuhan material tinggi, konsumerisme menggila, maka ia ditinggalkan.

\section{Saran}

Akar formalitas agama ada pada kesalah pahaman tentang makna iman dan agama, sehingga saran dari penelitian ini adalah aktivitas yang melampaui formalitas agama yang berarti mengangkat agama ke tempat yang seharusnya yakni sebagai spiritual hidup.

\section{DAFTAR PUSTAKA}

\section{Buku}

Asyhadie, Zaeni. 2013. "Aspek-Aspek Hukum Jaminan Sosial Tenaga Kerja Di Indoensia”. Jakarta. RajaGrafindo Persada.

Marzuki, Peter Mahmud. 2017. “Pengantar Ilmu Hukum” Jakarta. Kencana

Taufiqurrohman Syahuri, 2011, Tafsir Konstitusi Berbagai Aspek Hukum, Jakarta: Kencana Prenada Media Group. 
KRTHA BHAYANGKARA | Volume 15 Number 2, December 2021

\section{Perundang-undangan}

Undang - Undang No. 13 Tahun 2003 Tentang Ketenagakerjaan

Undang - Undang No. 11 Tahun 2020 Tentang Cipta Kerja

Peratuan Pemerintah No. 35 Tahun 2021 Tentang Perjanjian Kerja Waktu Tertentu, Alih Daya, Waktu Kerja dan Waktu Istirahat, dan Pemutusan Hubungan Kerja.

\section{Jurnal}

Aryo, Wisnu. 2020. "Problematika Pembentukan RUU cipta kerja dengan konsep omnibus law" Jurnal Panorama Hukum, Vol.1 No.5

Ima Mayasari, 2020, Kebijakan Reformasi Regulasi Melalui Implementasi Omnibus Law Di Indonesia, Jurnal Rechvinding Vol 9 No 1.

Prabowo, Adhi Setyo Dkk., 2020, "Politik Hukum Omnibus Law di Indonesia”, Jurnal Pamator, Vol.13, No.1.

Saputra. Rahmat (2020). Kedaruratan Dalam Perspektif Hukum Responsif: Studi Kasus Pembatasan Sosial Berskala Besar di Indonesia. KRTHA BHAYANGKARA, 14(2). https://doi.org/10.31599/krtha.v14i2.523

Suwandi Arham, 2020, Omnibus Law Dalam Perspektif Hukum Indonesia, Vol 7, No. 2.

Tohadi. 2020 "Kajian Kritis atas kewenangan Presiden untuk membatalkan Peraturan daerah dalam Omnibuslaw”, Jurnal Rechts Vinding, Vol.9 No.1 